\title{
EL PROBLEMA DE LA ORIGINALIDAD EN LATINOAMÉRICA
}

Pocas, limitadamente pocas, han sido las culturas que han tenido una especial preocupación por su originalidad como la cultura latinoamericana. Una preocupación que vemos surgir en los grupos culturales que, en estos últimos años, originan a las nuevas naciones que han aparecido en Asia y Africa. Preocupación, podemos anticipar, que ha nacido de la especial situación que en el pasado ha guardado Latinoamérica, y en el presente el mundo afroasiático con la cultura llamada Occidental. Pues ha sido el impacto de ésta, como producto de la expansión de los hombres que la hicieron posible, la que ha originado la preocupación por la originalidad a que me refiero. Porque eso es, originalidad, originalidad en relación o frente a algo y este algo lo es la cultura occidental. Es natural que esta preocupación surgiese con una gran fuerza, como surgió, en Latinoamérica: conquistada y colonizada por una expresión de la cultura europea, la representada por el mundo ibérico; y sometida a presión por la expansión de otro aspecto de esa misma cultura, la que hemos llamado occidental, impulsada por las grandes naciones de la Europa occidental: Inglaterra, Francia, Holanda, Alemania y llevada a su máxima realización en los Estados Unidos de Norteamérica. A las mismas dominaciones y presiones se encontraron sometidos los pueblos afroasiáticos; sin embargo, la resistencia de sus respectivas culturas, desarrolladas o primitivas, fue superior a la que pudieron ofrecer las culturas precolombinas que fueron aplastadas y asimiladas por la cultura de sus conquistadores ibéricos. Fueron estos mismos conquistadores, los que fracasaron en el mundo afroasiático para ser substituidos, a partir del siglo xvIr por franceses, ingleses y alemanes que se contentaron con el dominio político y económico de esas regiones haciendo caso omiso del dominio cultural de las mismas. Será posteriormente, y como resultado natural de ese dominio, que los pueblos afroasiáticos, se incorporen culturalmente a la cultura occidental, planteándose dentro de ellos en estos días, como desde hace cerca de dos siglos en Latinoamérica, el problema de la originalidad de sus respectivas culturas, en función, precisamente, con la cultura occidental por ellos asimilada.

Ahora bien, más que un problema respecto a la originalidad de la cultura - latinoamericana es un problema respecto a la situación que guarda la cultura latinoamericana en relación con la cultura de la que se sabe hija o apéndice, la cultura europea u occidental. A los latinoamericanos, como posteriormente a los afroasiáticos, no les importará ser tanto diversos, distintos, originales, como saber qué son dentro de una cultura que resulta ser el principal instrumento de su 
existencia como pueblos o, más ampliamente, naciones. $\mathrm{Y}$ no podía ser de otra forma, ante una cultura que como la europea se ha presentado siempre como la Cultura por excelencia y a sus hacedores, sus hombres, como la expresión del Hombre; independiente de reacciones tanto latinoamericanas como afroasiáticas que hablan de volver a los orígenes culturales con abandono absoluto de toda expresión europea $\mathrm{u}$ occidental; reacción que no es sino la violenta expresión de una sola y única preocupación, saber qué sitio se guarda dentro de la cultura frente a la que se reacciona por no estar de acuerdo con el lugar que parece se le concede. Frente a tal cultura no quedaban sino dos caminos, su rechazo absoluto o su aceptación pero haciendo de ellas una cultura universal, esto es, de una amplitud tal que dentro de la misma cupiesen todos los hombres y culturas existentes, con independencia de cualquier diferenciación geográfica o racial. Auténtica universalización de la cultura europea y occidental que tropezará, una y otra vez, con el limitado espiritu de la mayoría de sus hacedores, afianzados en un exclusivismo que impedía el reconocimiento de los grandes valores, por ellos declarados, en otros hombres y pueblos que no fuesen los propios.

La expresión de este exclusivismo que se opone a la universalización de la cultura europea se hace expresa en la polémica sobre América y sus hombres, entre Sepúlveda y De las Casas. Exclusivismo frente a universalismo. Negación de la humanidad del hombre americano y ampliación del humanismo a todos los hombres, con independencia de su raza y cultura. Un cristianismo limitado que no puede ver en otros hombres sino bestias, o engendros del demonio; frente al cristianismo amplio, universal, que reconoce la humanidad de todos los hombres y los incorpora en su seno. El humanismo que justifica la codicia de conquistadores y colonizadores frente al humanismo de la Filosofía de Cristo de los Vives, Vitoria y otros grandes erasmistas hispanos que soñaban con un imperio cristiano, al que han de ir incorporándose, en un plano absoluto de igualdad, todos los pueblos, todas las naciones del mundo y sus hombres. Ser parte activa, en un plano absoluto de igualdad, del imperio cristiano, o de la que posteriormente será llamada civilización o cultura occidental, será la gran preocupación de los hombres y pueblos allende los mares, en las Américas, la misma preocupación que surge en este siglo $\mathrm{xx}$, en los pueblos y hombres de Asia y Africa.

La preocupación por la originalidad en Latinoamérica, estriba así, no tanto en lo que Latinoamérica tenga de diferente, distinto, como en lo que tenga de común con Europa o el Occidente. Su preocupación es mostrar que sus hombres y sus obras son iguales, semejantes; por lo que de igual y semejante tienen todos los hombres. No, desde luego, con un espíritu de imitación, repetición, sino con el mismo espíritu que ha hecho posible la cultura europea y sus bienes $y$ valores. No es imitando a Europa en sus frutos que se forma parte de su cultura, sino actuando con el espíritu que ha hecho posibles esos frutos. Ser original no es rechazar o imitar, sino ser simplemente hombre, ese gran valor que ha expresado en toda su plenitud la cultura euro- 
pea y mantenido, aunque solo para sí misma la cultura Occidental. Esto es, ser original como lo es Europa. Europa es original porque ha creado y crea sin preocuparse en ser distinto, de imitar o no, ya que simplemente actúa, hace cultura, origina valores y bienes. Es esta capacidad, esta forma de originalidad, la que debe ser imitada, esto es, seguida, por Latinoamérica. El espíritu que ha hecho posible a la cultura europea, es el espíritu que debe animar a los latinoamericanos para que puedan ser originales, esto es, para que puedan originar cultura. El maestro venezolano, Andrés Bello, decía: "Nuestra civilización será también juzgada por sus obras; y si se la ve copiar servilmente a la europea, aún en lo que ésta no tiene de aplicable, ¿cuál será el juicio que formará de nosotros un Michelet, un Guizot? Dirán: la América no ha sacudido aún sus cadenas; se arrastra sobre nuestras huellas con los ojos vendados; no respira en sus obras un pensamiento propio, nada original, nada característico: remeda las formas de nuestra filosofía y no se apropia de su espíritu. Su civilización es una planta exótica que no ha chupado todavía sus jugos a la tierra que la sostiene." La originalidad es así, pura y simplemente, una actitud, la actitud propia del hombre, todo hombre, frente a su realidad. Esto ha sido Europa, esto ha sido la Cultura llamada occidental, esto debe ser Latinoamérica, la cultura latinoamericana que, por serlo, no por esto deje de ser simplemente cultura, la Cultura que todo hombre, todos los hombres han venido haciendo $\mathrm{y}$ hacen a través de la historia.

Ahora bien, cuando esta actitud, esta forma de originalidad, no es reconocida, aceptada por Europa o el Occidente, surge la rebelión. Una rebelión que puede, inclusive, tomar, como se dijo, la forma del rechazo absoluto de esa cultura. Tal es la actitud que toma Hispanoamérica frente a España provocando la ya conocida reacción de libertadores, como Bolívar, o emancipadores mentales como Sarmiento, Bilbao, Mora, Lastarria, Montalvo, Martí y otros muchos. Romper con España y su cultura, con el mundo por ella representado, con la cristiandad limitada que la misma ha expresado. Romper, rebelarse, porque no ha sabido estar a la altura de su propia cultura, por sus limitaciones, por haber impedido a los pueblos de esta América formada por ella concederles el lugar que en derecho les debería corresponder si sus ideas e ideales fuesen ciertos. Pero esta rebeldía y, con ella, la ruptura y separación de estas naciones frente a su Metrópoli, no es una reacción contra la cultura hispana por ellos heredada, sino contra la incapacidad de sus hombres para reconocer en otros hombres los valores que esa cultura ha pregonado. Es la misma reacción que vemos repetirse en nuestros días en la casi totalidad de los pueblos llamados del Tercer Mundo, que se han alzado o se alzan contra sus metrópolis, no para combatir la cultura por ellas levantada, sino como reacción contra la incapacidad de las mismas para reconocer su universalidad. Rebeldía contra el angostamiento de una cultura, contra su espíritu exclusivista. Así fue en Latinoamérica al iniciarse el movimiento que le concediera independencia política, y al reaccionar contra los 
hábitos y costumbres que, en su opinión, estaban destinados a hacerle aceptar el papel de subordinada. Los emancipadores americanos, lo que es también válido para los Estados Unidos frente a la Metrópoli inglesa, ante la incomprensión europea se han visto obligados a romper con sus metrópolis, pero, desde luego, no con su cultura. No es una rebeldía contra la cultura de que se consideran hijos, sino contra el tutelaje que en nombre de la misma se quiere seguir manteniendo. Por ello, una vez rotas las ligas políticas, su gran preocupación será reincorporarse a la cultura europea, pero en otra situación que no sea ya de subordinados. Reincorporarse como factores activos, responsables. Incorporarse como actores, no como simples imitadores o comparsas. $\mathrm{Y}$ pretender esto no implica ruptura alguna. "No es esto renegar de los progresos de la ciencia europea - decía el chileno Victorino Lastarria- ni pretender borrarlos para comenzar esa penosa y larga carrera que la inteligencia ha hecho en el viejo mundo para llegar a colocarse donde está." No, de lo que se trata es de ser fiel al espíritu de esa ciencia o cultura. " ¿Estaremos condenados todavía -agregaba Andrés Bello- a repetir servilmente las lecciones de la ciencia europea, sin atrevernos a discutirlas, a ilustrarlas con aplicaciones locales, a darles una estampa de nacionalidad?" Si así fuese seríamos infieles al espíritu de la cultura europea de la cual pretendemos ser parte activa. "iJóvenes chilenos! - agregaba-. Aprended a juzgar por vosotros mismos; aspirad a la independencia de pensamiento. Bebed en las fuentes; a lo menos en los raudales más cercanos a ellas... interrogad a cada civilización en sus obras; pedid a cada historiador sus garantías. Esa es la primera filosofía que debemos aprender de Europa."

La preocupación por la originalidad adquiere, así, el carácter de universalización. Ser original, no es ser limitado, sino universal. Implica la capacidad para elegir y adoptar todos los valores de la cultura, no sólo los valores de la llamada cultura europea u occidental, sino el espíritu que ha hecho de ella una cultura universal, al haber resumido los valores existentes de la historia del hombre. Porque esto es la cultura europea u occidental, cultura universal, como máxima expresión del Hombre. $\mathrm{Y}$ están los latinoamericanos, precisamente, contra quienes limiten el alcance de esta cultura, que siendo universal por sus orígenes, debe serlo también por sus metas. $\mathrm{Y}$ resulta, así paradójico, que el creador y directo heredero de esa cultura, el europeo u occidental, a fuerza de concebirse universal acaba por limitar los alcances de su cultura pretendiendo hacer de ella algo exclusivo a sus pueblos y lo que es más, a su raza. De esta forma, grandes porciones de la vida humana quedan fuera de su alcance, al margen de lo que consideran lo humano por excelencia. Salvaje o bárbaro son los calificativos que se han venido dando a los hombres de otros pueblos desde los inicios mismos de la cultura europea, pese a que esta cultura se ha caracterizado por un alto espíritu de asimilación. Asimilación que enarbolarán los llamados pueblos marginales frente a la actitud discriminatoria de una cultura que les ha enseñado tal espíritu. "Pueblos magistrales - dice Alfonso Reyes refiriéndose a 
los europeos- que, por bastarse a sí propios han vivido amurallados como la antigua China, y mil veces nos han dado ejemplo de la dificultad con que salen de sus murallas. Es entre nosotros un secreto profesional que el europeo medio se equivoca frecuentemente en las referencias a nuestra geografía, a nuestra historia, a nuestra lengua." Esto es, se trata ya de pueblos que con abandono de la universalidad del espíritu que hizo posible la universalización de su cultura, han hecho de sus limitaciones fundamentos de universalidad y de sus ignorancias, la máxima expresión de lo absoluto. Frente a esta actitud, agrega Reyes, los pueblos y hombres considerados marginales, subhombres, declaramos: "Somos una parte integrante y necesaria en la representación del hombre por el hombre. Quien nos desconoce es un hombre a medias."

La originalidad, como expresión de universalidad, vendrá a ser la idea central de la preocupación filosófica en Latinoamérica. Una preocupación que encontramos a través de la historia del pensamiento o filosofía latinoamericanos. Allí está entre otros, el maestro argentino, Juan Bautista Alberdi en su famoso curso sobre la filosofía americana. Para el pensador argentino la filosofía no es una simple abstracción. Y si por universalidad se quiere decir abstracción, "La filosofía no es universal, porque no hay una solución universal... Cada país, cada época y cada escuela han dado soluciones distintas de los problemas del espíritu humano." $\mathrm{Y}$ es de esta forma de enfrentarse a la realidad y solucionar sus problemas que surge la originalidad y se puede hablar de una filosofía griega, europea $y$, por qué no, americana. Pero ser original no quiere decir olvidar, hacer a un lado las múltiples experiencias del espíritu humano. No, la originalidad es, precisamente, la capacidad que posee el hombre para seleccionar, para combinar y utilizar esas experiencias. Así habrá que acudir a todas las experiencias, conociéndolas para aprovecharlas o descartarlas, según sean las necesidades y los problemas que hayan de ser resueltos. No imitar, inventar, combinar, utilizar, que esto es lo que ha hecho siempre la filosofía europea, que en esto descansa su originalidad. Lo importante es que no sea una abstracción ajena al hombre. "Hemos nombrado la filosofía americana -dice Alberdi-, y es preciso que hagamos ver que ella puede existir. Una filosofía completa es la que resuelve los problemas que interesan a la humanidad. Una filosofía contemporánea es la que resuelve los problemas que interesan por el momento. Americana será la que resuelva el problema de los destinos americanos." Esto es, esto ha sido la filosofía en Europa, en esto ha estribado su originalidad. ¿En qué ha consistido su universalidad? De su originalidad se ha derivado su universalidad al ser las soluciones, propias de sus problemas, soluciones también válidas para otros pueblos y hombres. Esto será la filosofía americana, si es auténticamente original, esto es, si es el resultado de un enfrentamiento a la realidad. De una manera u otra los pueblos latinoamericanos se enfrentarán con problemas con los que también se enfrentan los hombres de otros continentes y por lo mismo, sus soluciones, si son auténticas, tendrán validez para esos otros hombres. Serán experiencias válidas 
para ellos, como lo son para los latinoamericanos las experiencias de otros pueblos y hombres que de una manera u otra se encuentren en circunstancias semejantes.

La filosofía como expresión de las experiencias de todos los hombres y pueblos, como resumen abstracto de las múltiples soluciones que han dado a sus problemas, resulta universal, eterna, válida para los hombres de hoy como puede serlo para los de mañana y lo fue para los de ayer. "La filosofía - dice el pensador mexicano José Vasconcelos- es eterna y está esperando siempre la contribución de todos los pueblos. Nosotros en América estamos en posición ventajosa para construir." ¿De dónde proviene esa ventaja? Nosotros, sigue Vasconcelos, a diferencia de los europeos, pese a que ellos han sido los más grandes maestros de la historia, no consideramos nuestras experiencias como la única experiencia del hombre, sabemos que hay otros hombres que pueden, también, aportarnos sus experiencias. "En nuestros pueblos - dice- podéis preguntar a un niño de Cuba, Colombia o cualquier país de esta América sobre los hombres más grandes de la historia y os dirán Sócrates, Platón, el Dante... hacedle la misma pregunta a un niño norteamericano y dirá Edison, Lincoln o Henry Ford. Lo mismo acontecerá con un francés y de otras nacionalidades. $Y$ es que en filosofía esos pueblos están llenos de prejuicios de raza y no prescinden de englobar a persónalidades nacionales, no tienen la libertad espiritual de nuestra raza, que no arrastra prejuicios." De allí su ideal de una América como crisol de razas y culturas, de donde una sola raza, una raza cósmica, una sola cultura, una sola filosofía que resumiendo todas las experiencias y soluciones del hombre a través de la historia, of rezca soluciones válidas para todos o la mayoría de los hombres. De esta forma la originalidad, el punto de partida original, la realidad concreta de cada hombre y pueblo, se transformará en universalidad como resumen de todas ellas. En eso mismo soñaba, en ya lejano pasado, ese gran libertador de pueblos que fue Simón Bolívar, que hablaba no sólo de la unidad de todos los pueblos latinoamericanos, por la comunidad de problemas y sus necesarias soluciones, sino de toda América y de todo el mundo, por las mismas razones, hasta crear una comunidad universal de pueblos iguales entre iguales, de hombres entre hombres.

De lo original, como expresión de lo concreto en el hombre y en los pueblos, a lo universal como expresión de lo que todos los hombres y pueblos tienen de común. Tal sería la preocupación espiritual y filosófica de los latinoamericanos en sus relaciones con otras culturas y hombres, concretamente en su relación con la cultura europea u occidental, de donde han asimilado estas ideas, pese a que sus creadores parecían haberlas olvidado para adoptar la actitud exclusivista a que hemos hecho antes referencias. Originalidad, como punto de partida, para que el latinoamericano se conozca y sepa de sus posibilidades, las propias como hombre dentro de una determinada circunstancia, y, a partir de ellas participar en una tarea que debe ser universal, de todos y para todos los hombres. El maestro mexicano, Justo Sierra, ha resumido este paso de la originalidad a la 
universalidad con las siguientes palabras: "A nosotros toca demostrar que nuestra personalidad tiene raíces indestructibles en nuestra naturaleza y en nuestra historia: que, participando de los elementos de otros pueblos americanos, nuestras modalidades son tales, que constituye una entidad perfectamente distinta de otras." Por su realidad, por sus circunstancias naturales y culturales unos hombres son distintos de otros, pero no tan distintos que unos u otros dejen de ser considerados como hombres. La Humanidad es üna, con independencia de la diversidad de hombres que la forman, con independencia no sólo de las diversidades raciales o culturales, sino pura y simplemente personales. Cada hombre, como cada pueblo, tiene su personalidad y es esa personalidad la que le hace, precisamente, ser parte de la humanidad, ser un hombre entre hombres. De alli que una vez definida la personalidad de un pueblo y la de sus hombres, ha de pasarse a una tarea más universal y por ende humana, a las tareas que reclaman los diversos problemas como los que enfrentan, no sólo un grupo de hombres, sino todos los hombres. Pero - decía Sierra- "Para que no sea sólo mexicana, sino humana esta labor", no se podrá olvidar que será "necesario vivir en conexión íntima con el movimiento de la cultura universal". Todos los hombres $\mathrm{y}$ todos los pueblos marchan hacia una misma meta, buscan fines semejantes, la misma y única verdad. Latinoamérica no puede ser una excepción. "Debemos y queremos tomar nuestro lugar - dice el maestro mexicano- en esa divina precesión de antorchas." Originales, pero haciendo de la originalidad punto de partida para la universalidad. Latinizar el saber, hacerlo propio, venga de donde viniere. Acrecentar la propia personalidad, la propia originalidad, asimilando la cultura de otros pueblos. Por lo que se refiere a la cultura europea u occidental, universalizarla, al ampliar la originalidad de la misma en la asimilación que de ella hagan otros pueblos del mundo. No más, pero tampoco menos.

De esta forma lo que hemos llamado el problema de la originalidad en Latinoamérica resulta ser el problema que ahora, como ayer esta América, afrontan otros pueblos del mundo en ineludible relación con la cultura originaria de Europa, con la cultura que la expansión occidental convirtió en bien universal. Muchos de los grandes conflictos de nuestros días, repito, resultan ser la consecuencia de la universalización de la cultura originada en Europa o el llamado mundo occidental. Una cultura que por sus alcances ha dejado de ser exclusivamente europea $\mathrm{u}$ occidental, una cultura cuyos valores son ahora enarbolados por pueblos que al descubrirse, por obra de la misma, como hombres entre hombres, la reclaman como propia y exigen, también, un lugar en la procesión de antorchas de la misma. Como iguales, como hombres entre hombres, como pueblos entre pueblos. Fue en esto que soñaron los Bolívar, Martí, Sarmiento, Lastarria, Justo Sierra, Vasconcelos y otros muchos maestros del pensamiento y la filosofía latinoamericanos, como ahora sueñan otros hombres en Asia, Africa $\mathrm{y}$ todos los pueblos que se han denominado del Tercer Mundo y que aspiran a serlo de uno solo.

LEOPOLDO ZEA 